\title{
Fermentation of deproteinized cheese whey powder solutions to ethanol by engineered Saccharomyces cerevisiae: effect of supplementation with corn steep liquor and repeated-batch operation with biomass recycling by flocculation
}

\author{
Ana Carina Silva • Pedro M. R. Guimarães • \\ José A. Teixeira • Lucília Domingues
}

Received: 15 April 2010/Accepted: 20 May 2010/Published online: 10 June 2010

(C) Society for Industrial Microbiology 2010

\begin{abstract}
The lactose in cheese whey is an interesting substrate for the production of bulk commodities such as bio-ethanol, due to the large amounts of whey surplus generated globally. In this work, we studied the performance of a recombinant Saccharomyces cerevisiae strain expressing the lactose permease and intracellular B-galactosidase from Kluyveromyces lactis in fermentations of deproteinized concentrated cheese whey powder solutions. Supplementation with $10 \mathrm{~g} / \mathrm{l}$ of corn steep liquor significantly enhanced whey fermentation, resulting in the production of $7.4 \%$ (v/v) ethanol from $150 \mathrm{~g} / \mathrm{l}$ initial lactose in shake-flask fermentations, with a corresponding productivity of $1.2 \mathrm{~g} / \mathrm{l} / \mathrm{h}$. The flocculation capacity of the yeast strain enabled stable operation of a repeated-batch process in a 5.5-1 air-lift bioreactor, with simple biomass recycling by sedimentation of the yeast flocs. During five consecutive batches, the average ethanol productivity was $0.65 \mathrm{~g} / \mathrm{l} / \mathrm{h}$ and ethanol accumulated up to $8 \%(\mathrm{v} / \mathrm{v})$ with lactose-toethanol conversion yields over $80 \%$ of theoretical. Yeast viability $(>97 \%)$ and plasmid retention $(>84 \%)$ remained high throughout the operation, demonstrating the stability and robustness of the strain. In addition, the easy and inexpensive recycle of the yeast biomass for repeated utilization makes this process economically attractive for industrial implementation.
\end{abstract}

A. C. Silva · P. M. R. Guimarães · J. A. Teixeira ·

L. Domingues $(\square)$

IBB-Institute for Biotechnology and Bioengineering,

Centre of Biological Engineering, Universidade do Minho,

Campus de Gualtar, 4710-057 Braga, Portugal

e-mail: luciliad@deb.uminho.pt
Keywords Cheese whey - Corn steep liquor · Ethanol production · Flocculation - Recombinant . Saccharomyces cerevisiae

\section{Introduction}

Cheese whey is the main by-product of cheese manufacturing. It has been traditionally regarded as a polluting waste stream, although it has many applications and a huge potential as a source of added-value compounds, since it retains the majority of milk nutrients $[15,44]$. In particular, whey proteins have many added-value applications in the food industry, because of their high nutritional and functional values [45]. Therefore, the paradigm in whey handling has been progressively moving from the environmental treatment of a waste by-product to the economical valorization of a valuable co-product.

The fermentation of lactose in cheese whey to ethanol has been for long under consideration in the framework of sustainable whey valorization plans. Particularly, after the separation of whey proteins by ultrafiltration or diafiltration to produce whey protein concentrates [45], the lactose is obtained in the permeate stream that can be fermented to produce potable or fuel bio-ethanol. We have estimated that the current lactose surplus that could be converted to ethanol may amount to over 4 million tonnes per year, which could yield about 2.3 million $\mathrm{m}^{3}$ of ethanol (i.e., $3.5 \%$ of the world production in 2008) [15]. Besides, a lactose fermentation process strongly reduces the polluting load of the whey permeate, contributing to solve the environmental pressure caused by whey surplus.

Industrial processes for the direct fermentation of whey or whey permeate to ethanol are economically hindered by the low lactose concentration (ca. $5 \% \mathrm{w} / \mathrm{v}$ ) that limits the 
theoretical ethanol titer to $3.4 \%$ (v/v). Higher ethanol levels are strongly desirable to minimize capital costs and distillation energy. Therefore, whey may be concentrated by ultrafiltration and/or reverse osmosis processes prior to fermentation. Alternatively, whey powder (ca. $70 \% \mathrm{w} / \mathrm{w}$ lactose) may be added to increase the lactose concentration of native whey [17, 22], or the sugar concentration may be increased by adding other high-sugar condensed materials, such as molasses, to the native whey [25, 34].

An adequate supply of specific nutrients, such as nitrogen, phosphorus, trace elements, and vitamins, is required to obtain a rapid and complete fermentation process. Hence, for industrial applications, it is necessary to exploit inexpensive nutrient sources that can supply all nutritional requirements for microbial growth and fermentation. Corn steep liquor (CSL), a major by-product of corn starch processing, is an inexpensive source of proteins, amino acids, minerals, vitamins, and trace elements and has been often reported as a rich and effective nutritional supplement [1, 2, 21, 26, 27]. In particular, it constitutes a costeffective alternative to the widely used but expensive peptone and yeast extract supplements.

Yeast strains of the species Kluyveromyces marxianus (which currently includes former species $K$. fragilis) and its anamorph form Candida pseudotropicalis have been the most widely exploited for the conversion of lactose to ethanol [15]. Moreover, several process engineering and/or genetic engineering strategies have been devised in order to accomplish lactose fermentation using Saccharomyces cerevisiae, whose wild strains lack a lactose metabolization system (for reviews see $[6,15]$ ). We have transferred the LAC12 (encoding the lactose permease) and LAC4 (encoding the intracellular B-galactosidase) genes of Kluyveromyces lactis into a strongly flocculent $S$. cerevisiae host strain, obtaining a slow lactose-fermenting recombinant strain [8]. In such strain, glucose/galactose diauxy is avoided in lactose media since the lactose is first transported to the interior of the cell by the permease and then intracellularly hydrolyzed to glucose and galactose by the B-galactosidase. This recombinant was improved through a long-term evolutionary engineering experiment, resulting in an evolved strain that displayed a strongly enhanced lactose fermentation phenotype [13]. We identified two molecular events that targeted the $L A C$ construct in the evolved strain, namely a deletion of 1,593 base pairs in the intergenic region between $L A C 4$ and $L A C 12$ (region that works as promoter for the divergent transcription of both $L A C$ genes in $K$. lactis) and a decrease of the plasmid copy number by tenfold compared to that in the original recombinant. Furthermore, the results suggested that these events contributed to tuning the expression of the $L A C$ genes resulting in the improved lactose fermentation phenotype [13]. The strongly flocculent phenotype of the strain has a number of advantages from the process viewpoint, permitting the separation of yeast biomass from the fermentation broth by sedimentation instead of costly centrifugation steps and allowing simple and fast yeast recycling for repeated-batch or cell retention for continuous operation.

We have previously studied the fermentation performance of the evolved strain using mineral medium with concentrations of lactose up to $200 \mathrm{~g} / \mathrm{l}$ [14]. In this study, we extend that investigation to the fermentation of deproteinized concentrated cheese whey. Specifically, we tested the effect of supplementing the whey with CSL and scaled-up the fermentations to $5.51 \mathrm{in}$ an air-lift bioreactor establishing a repeated-batch process with cell recycling by flocculation.

\section{Materials and methods}

\section{Yeast}

The yeast used was a recombinant $S$. cerevisiae flocculent strain, NCYC869-A3/T1-E (or simply T1-E), expressing both the LAC4 and LAC12 genes of K. lactis from a multicopy plasmid. This strain is a derivative of the transformant NCYC869-A3/T1 [8] and was obtained by a long-term evolutionary engineering experiment [13].

\section{Media and fermentations}

The yeast for inoculation was grown in Erlenmeyer flasks filled to $40 \%$ of the total volume with defined mineral medium [48] containing $20 \mathrm{~g} / \mathrm{l}$ lactose and doubled concentrations of trace elements and vitamins. To avoid major drops in $\mathrm{pH}$ during cultivation, the medium was supplemented with $100 \mathrm{mM}$ potassium hydrogen phthalate. The initial $\mathrm{pH}$ was adjusted to 4.5 with $\mathrm{NaOH}$. After incubation at $30^{\circ} \mathrm{C}$ and $150 \mathrm{rpm}$ for $36-40 \mathrm{~h}$, the cell suspension was aseptically collected by centrifugation $(10 \mathrm{~min}$ at 7,500 $\times \mathrm{g}$, $4^{\circ} \mathrm{C}$ ) and resuspended in the supernatant to $200 \mathrm{mg}$ fresh yeast $/ \mathrm{ml}$. An appropriate volume of this concentrated cell suspension was then used to inoculate the fermentations.

The medium for fermentations consisted in cheese whey powder solutions (CWPS) with or without CSL supplementation, as indicated. The cheese whey powder was kindly supplied by a Portuguese dairy company (Lactogal). Its composition included (w/w) $>73 \%$ lactose, $12 \%$ proteins, $1.5 \%$ lipids, $<5 \%$ moisture. The CSL was kindly provided by a starch manufacturer (COPAM, Portugal). After autoclaving, the whole CSL was allowed to settle for $1-2$ days at $4{ }^{\circ} \mathrm{C}$ and then centrifuged $(15 \mathrm{~min}$ at $13,100 \times g)$ to remove the insolubles. The packed sediment, which was discarded, corresponded to $15 \%(\mathrm{w} / \mathrm{w})$ of the whole CSL. The composition of the centrifuged CSL (i.e., the supernatant after centrifugation) was as follows (w/w): $65 \%$ water 
(determined by drying overnight at $105^{\circ} \mathrm{C}$ ), $6.1 \%$ ash (determined by drying for $8 \mathrm{~h}$ at $500^{\circ} \mathrm{C}$ ), $3.4 \%$ free reducing sugars (determined by the DNS method [32] using glucose as standard), $2.2 \%$ total Kjeldahl nitrogen (determined using the Tecator Kjeltec 1026 system), 2.6\% fat (determined using the Tecator Soxtec HT2 system); density 1.14; pH 4.0.

For the preparation of media for shake-flask fermentations, an appropriate mass of cheese whey powder was dissolved in $0.5-11$ of distilled water and autoclaved $\left(115^{\circ} \mathrm{C}, 15 \mathrm{~min}\right)$. The precipitate (mostly proteins) was removed by centrifugation $(15 \mathrm{~min}$ at $13,100 \times g)$. The lactose content in the cleared solution was determined and the solution was diluted with sterile water in order to adjust the initial lactose concentration to the level desired for each experiment. For the preparation of the higher volumes (8-10 1) necessary for the bioreactor fermentations, after autoclaving $\left(121^{\circ} \mathrm{C}, 60-75 \mathrm{~min}\right)$ the CWPS were allowed to settle for 16-24 $\mathrm{h}$ at room temperature and then were decanted under sterile conditions in order to remove the precipitate. With this decantation procedure, some solids were transported to the cleared whey solution (the corresponding dry weight was 1-3 g/l, as opposed to ca. $0.02 \mathrm{~g} / \mathrm{l}$ in centrifuged whey solution). Nevertheless, comparative shake-flask fermentation trials showed no significant differences in the kinetics of fermentations with centrifuged or decanted CWPS.

Shake-flask fermentations were done in Erlenmeyer flasks filled to $40 \%$ of the total volume with CWPS medium and incubated at $30^{\circ} \mathrm{C}, 150 \mathrm{rpm}$. The initial $\mathrm{pH}$ of the CWPS was $5.8 \pm 0.1$ and the $\mathrm{pH}$ at the end of fermentations decreased to $5.0 \pm 0.4$. Fermentations were inoculated with $5 \mathrm{~g}$ fresh yeast/l.

Bioreactor fermentations were done in an air-lift reactor (internal recirculation type through a concentric draft tube with an enlarged degassing zone; made in-house) with a working volume of 5.51 (for details see [7, 24]). The temperature was controlled at $30 \pm 1^{\circ} \mathrm{C}$. The $\mathrm{pH}$ of the whey solutions was adjusted to $4.2 \pm 0.2$ (to minimize possible bacterial contaminations) with concentrated $\mathrm{HCl}$ before pumping into the bioreactor, and no major changes were observed during the fermentations ( $\mathrm{pH}$ values measured in samples kept at $4.2 \pm 0.2$ ) due to the inherent buffering capacity of the whey solutions. The system was aerated with sterile air at a flow rate of $0.1 \mathrm{vvm}$.

For repeated-batch operation, the yeast biomass was recycled by flocculation. Hence, at the end of each batch run the aeration was stopped for $15 \mathrm{~min}$, allowing the flocculated biomass to sediment at the bottom of the bioreactor. The cleared fermentation broth was then removed though the feeding port (runs 1 and 2) or the sampling port (runs 3 and 4). The volume retained in the bioreactor (flocculated biomass + fermentation broth) was therefore $250 \mathrm{ml}$ (runs 1 and 2) and 1.11 (runs 3 and 4). The aeration was then restarted and fresh medium was fed to the bioreactor to start the subsequent fermentation run. The initial batch (run 1) in each cycle of fermentations was inoculated with $2.5 \mathrm{~g}$ fresh yeast/l.

\section{Analytical procedures}

Cell dry weight was determined using 15-30 ml samples of the yeast culture collected by centrifugation $(10 \mathrm{~min}$ at $\left.7,500 \times g, 4^{\circ} \mathrm{C}\right)$ in a pre-weighed dried tube and then washed with $40 \mathrm{ml}$ of distilled water. The tube was dried overnight at $105^{\circ} \mathrm{C}$ and weighed again. Lactose, ethanol and glycerol were analyzed by HPLC, using a Varian MetaCarb $87 \mathrm{H}$ column eluted at $60^{\circ} \mathrm{C}$ with $0.005 \mathrm{M} \mathrm{H}_{2} \mathrm{SO}_{4}$ at a flow rate of $0.7 \mathrm{ml} / \mathrm{min}$, and a refractive-index detector. Plasmid retention, i.e., the fraction (\%) of plasmid-bearing cells, was determined as previously described [13]. Briefly, samples from the yeast culture were washed twice with a $15 \mathrm{~g} / \mathrm{l} \mathrm{NaCl}$ pH 3.0 solution to deflocculate cells and aliquots of appropriate dilutions were spread onto YPGal plates (1\% yeast extract, $2 \%$ peptone, $2 \%$ galactose, $2 \%$ agar) supplemented with $40 \mathrm{mg} / 1$ Xgal (5-bromo-4-chloro-3-indolyl- $\beta$-D-galactopyranoside). The fraction of plasmid-bearing cells was determined as the ratio between the number of blue colonies (corresponding to cells expressing $\beta$-galactosidase, i.e., those that carry the plasmid) and the total number of colonies (blue + white). Yeast viability was determined by methylene blue staining [33] after washing the yeast samples twice with deflocculating solution, and calculated by the ratio between viable (non-stained) and total cell counts.

\section{Determination of fermentation parameters}

Ethanol conversion yield was calculated by the ratio between the maximum ethanol concentration produced and the lactose consumed (difference between the initial and residual lactose concentrations). It was expressed as a percentage (\%) of the theoretical conversion yield, i.e., the yield considering a production of $0.538 \mathrm{~g}$ of ethanol per $\mathrm{g}$ of lactose. Ethanol productivity was defined as the ratio between final ethanol concentration and fermentation time. Statistical significance analysis was performed by one-way ANOVA, Tukey test, using the SigmaStat 3.10 (SYSTAT software).

\section{Results and discussion}

Effect of the supplementation of concentrated cheese whey (150 g/l lactose) with CSL and other nutrient sources

We have previously tested the recombinant strain T1-E for the batch fermentation of CWPS with $150 \mathrm{~g} / \mathrm{l}$ initial lactose 
in a stirred-tank bioreactor and found that, although the ethanol titer produced was acceptable $(55 \mathrm{~g} / \mathrm{l}$, which corresponds to $70 \%$ of the theoretical conversion yield), the fermentation was slow and therefore ethanol productivity was very low $(0.46 \mathrm{~g} / \mathrm{l} / \mathrm{h})$ [13]. However, in shake-flask fermentations with mineral medium, the same strain fermented $150 \mathrm{~g} / \mathrm{l}$ lactose producing $63 \mathrm{~g} / \mathrm{l}$ ethanol with a productivity over $1.5 \mathrm{~g} / \mathrm{l} / \mathrm{h}$ [14], which led us to hypothesize that nutrient limitation was impairing concentrated cheese whey fermentation.

Corn steep liquor is an inexpensive nutrient-rich source and has been often used as a supplement in several microbial fermentations. These include fermentations of cheese whey for the production of acetate by Clostridium formicoaceticum and Lactococcus lactis [19], succinic acid by Mannheimia succiniciproducens [27], and lactic acid by Lactobacillus spp. [23, 42] or Enterococcus flavescens [1]. However, to our knowledge, CSL has not been tested as a supplement for the production of ethanol from whey by yeast, even though it has been applied as supplement to ethanol fermentations from other substrates, namely glucose [26], xylose [2], and biomass hydrolysates [21, 47]. Therefore, we evaluated the effect of CSL supplementation $(5,10$, and $20 \mathrm{~g} / \mathrm{l})$ in shake-flask fermentations of deproteinized CWPS with approximately $150 \mathrm{~g} / \mathrm{l}$ initial lactose (Fig. 1). The addition of CSL strongly enhanced the lactose fermentation kinetics, resulting in increased lactose consumption and consequent higher ethanol production. Increasing the CSL concentration from 5 to $10 \mathrm{~g} / \mathrm{l}$ decreased the lactose residual and increased the ethanol concentration produced after $70 \mathrm{~h}$ of fermentation (Fig. 1). Moreover, the final biomass concentration (dry weight) increased from $12.4 \mathrm{~g} / \mathrm{l}(0 \mathrm{~g} / \mathrm{l} \mathrm{CSL})$ to $14.5 \mathrm{~g} / \mathrm{l}(5 \mathrm{~g} / \mathrm{l} \mathrm{CSL})$

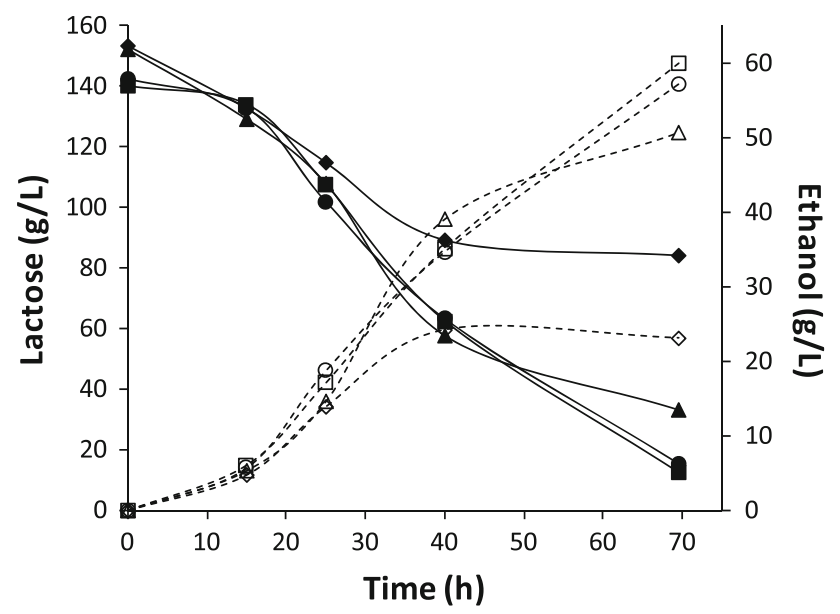

Fig. 1 Profiles of lactose consumption (solid symbols, solid lines) and ethanol production (open symbols, dashed lines) during shakeflask fermentations of concentrated whey supplemented with CSL: $0 \mathrm{~g} / 1$ (diamonds), $5 \mathrm{~g} / 1$ (triangles), $10 \mathrm{~g} / 1$ (squares) and $20 \mathrm{~g} / 1$ (circles) and $16.2 \mathrm{~g} / \mathrm{l}(10 \mathrm{~g} / \mathrm{l} \mathrm{CSL})$. However, a further increase to $20 \mathrm{~g} / \mathrm{l} \mathrm{CSL}$ did not result in enhanced lactose to ethanol fermentation or yeast biomass production (final concentration of $15.9 \mathrm{~g} / \mathrm{l}$ ), and therefore, $10 \mathrm{~g} / \mathrm{l} \mathrm{CSL}$ was chosen as the optimal supplementation for further fermentation trials. We performed replicates of the shake-flask fermentations either without supplementation $(n=7)$ or with $10 \mathrm{~g} / \mathrm{l} \mathrm{CSL}$ addition $(n=9)$ (Table 1). The supplementation with CSL resulted in statistically significant ( $p$ value $<0.01)$ decrease of the final lactose residual and increase of the final ethanol titer (average relative increase of $76 \%$ ) to $58 \mathrm{~g} / \mathrm{l}$ (i.e., $7.4 \% \mathrm{v} / \mathrm{v})$. The overall ethanol productivity was also substantially improved by CSL addition (Table 1).

Besides CSL, we have tested supplementation with other nutrient sources, namely yeast extract $(5 \mathrm{~g} / \mathrm{l})$, ammonium sulphate $(5 \mathrm{~g} / \mathrm{l})$, and urea $(3 \mathrm{~g} / \mathrm{l})$ (data not shown). The addition of ammonium sulphate or urea did not improve considerably the fermentation of CWPS, indicating that the limiting nutrient in whey is not assimilable nitrogen. This is in agreement with previous observations in whey fermentations by Kluyveromyces spp. yeasts. In particular, Mahmoud and Kosikowski [31] observed that supplementation of concentrated whey permeate with ammonium sulphate did not affect ethanol production while addition of urea or peptone reduced ethanol production. Moreover, the results of Kargi and Ozmihci [22] suggested that the addition of ammonium chloride to whey stimulated cell growth but reduced ethanol formation. Conversely, supplementation with yeast extract, which similarly to CSL is a complex source of nutrients [18, 49], strongly enhanced the fermentation of lactose by strain T1-E. Compared with the $10 \mathrm{~g} / \mathrm{l} \mathrm{CSL}$ supplementation, $5 \mathrm{~g} / 1$ yeast extract supplementation resulted in higher initial fermentation rate, but the final lactose residual and the maximum ethanol titer reached were similar.

Effect of increasing the concentration of whey (to $200 \mathrm{~g} / \mathrm{l}$ lactose)

The utilization of media with a high lactose concentration is desirable from the industrial standpoint, since it potentially allows reaching a high ethanol titer at the end of fermentation therefore permitting a reduction in the distillation costs. In this perspective, we studied the effect of incrementing the CWPS concentration to obtain a medium with $200 \mathrm{~g} / \mathrm{l}$ initial lactose (Table 1). The yeast fermented ca. $60 \mathrm{~g} / \mathrm{l}$ of lactose but the fermentation stopped after about $43 \mathrm{~h}$. Unexpectedly, under these conditions, the supplementation of the concentrated whey with $10 \mathrm{~g} / \mathrm{l} \mathrm{CSL}$ did not have any considerable effect in the fermentation performance. In previous work, we have already observed that increasing lactose concentration in mineral medium 
Table 1 Data obtained at the end of shake-flask fermentations of concentrated whey with approximately 150 and $200 \mathrm{~g} / \mathrm{l}$ initial lactose with or without supplementation with $10 \mathrm{~g} / \mathrm{l} \mathrm{CSL}$

\begin{tabular}{|c|c|c|c|c|}
\hline CSL supplementation & 0 & 10 & 0 & 10 \\
\hline Initial lactose (g/l) & $157 \pm 6$ & $153 \pm 13$ & $202 \pm 10$ & $196 \pm 5$ \\
\hline Fermentation time $(\mathrm{h})$ & $44 \pm 4$ & $49 \pm 9$ & $43 \pm 4$ & $43 \pm 4$ \\
\hline Residual lactose (g/l) & $77 \pm 20$ & $20 \pm 18$ & $138 \pm 8$ & $142 \pm 8$ \\
\hline Ethanol $(\mathrm{g} / \mathrm{l})$ & $33 \pm 8$ & $58 \pm 7$ & $27 \pm 7$ & $25 \pm 5$ \\
\hline Glycerol (g/l) & $2.4 \pm 0.7$ & $3.4 \pm 0.7$ & $3.6 \pm 0.9$ & $3.5 \pm 1.0$ \\
\hline Biomass dry weight (gDY/l) & $12.4 \pm 2.3$ & $16.2 \pm 2.1$ & $9.0 \pm 1.5$ & $9.4 \pm 2.2$ \\
\hline Ethanol yield ( $\%$ of theoretical) & $76 \pm 8$ & $81 \pm 6$ & $79 \pm 8$ & $86 \pm 10$ \\
\hline Ethanol productivity (g/l/h) & $0.74 \pm 0.23$ & $1.22 \pm 0.27$ & $0.63 \pm 0.12$ & $0.57 \pm 0.07$ \\
\hline Final yeast viability (\%) & $98 \pm 1$ & $98 \pm 1$ & $98 \pm 1$ & $98 \pm 0$ \\
\hline Plasmid retention $(\%)$ & $82 \pm 6$ & $88 \pm 4$ & $85 \pm 2$ & $88 \pm 4$ \\
\hline
\end{tabular}

Values are average \pm standard deviation of seven or nine independent biological replicates for $150 \mathrm{~g} / \mathrm{l}$ initial lactose with 0 or $10 \mathrm{~g} / \mathrm{l} \mathrm{CSL}$, respectively, and three independent biological replicates for $200 \mathrm{~g} / \mathrm{l}$ initial lactose

from 150 to $200 \mathrm{~g} / \mathrm{l}$ led to slower or incomplete fermentations by T1-E [14], although the impact was much less pronounced than observed here.

The strong negative impact of increasing whey concentration on yeast fermentation performance may be attributed to the elevated osmotic pressure caused by high concentration of lactose and other cheese whey powder components. Accordingly, several authors have reported substrate inhibition effects on ethanol production and/or yeast growth, particularly at high initial lactose concentrations (150-200 g/l), for Kluyveromyces spp. [20, 35-37, 43] and Candida pseudotropicalis [11, 46]. The high ash content (particularly sodium and potassium) in concentrated whey has also been reported to inhibit yeast growth and ethanol formation by Kluyveromyces spp. [31].

There has been accumulated evidence that ethanol inhibition is more pronounced in the presence of high concentration of substrates such as glucose or lactose (see [3] and references therein). Hence, it is possible that relatively low concentrations of ethanol may exert strong negative impact in yeast fermentation when the substrate concentrations in the media are very high. This lactoseethanol synergistic effect was not strong enough to compromise cell viability (which remained high after $43 \mathrm{~h}$ of fermentation; Table 1) but could, for instance, repress and/or inactivate enzymes in the fermentation pathway, including the heterologous lactose permease and B-galactosidase expressed by the strain T1-E.

Repeated-batch whey fermentations in an air-lift bioreactor with biomass recycling by flocculation

The fermentations were scaled-up to 5.51 in an air-lift bioreactor in which the mixing was achieved by applying a $0.1 \mathrm{vvm}$ air flow through the internal recirculation tube.
This aeration rate was low enough so that the dissolved oxygen measured in mid-fermentation dropped to zero and the yeast metabolism was mainly fermentative. A low aeration regime may be beneficial to alcoholic fermentation, since yeast needs oxygen to synthesize important membrane lipids, namely sterols and unsaturated fatty acids [16]. The highly flocculent phenotype of the strain T1-E was exploited for repeated-batch operation, with the flocculated biomass being recycled simply by sedimentation as described in the section Materials and methods. This type of operation with flocculent yeasts has been very recently used by other authors for the production of fuel ethanol [4, 28, 30]. It provides several advantages of industrial relevance, including: (1) fast and convenient separation of yeast cells from the fermentation broth by sedimentation, thus avoiding costly centrifugation steps in the industrial process; (2) biomass accumulation along the consecutive batches for high-cell-density fermentations, which may represent gains in process productivity; (3) the system positively selects for the accumulation of flocculated cells, since free (nonflocculated) cells are removed with the cleared fermentation broth, which enhances operational stability; (4) prevention of contaminations, due to increased yeast cell densities and avoidance of centrifugation steps.

We started by testing the fermentation of deproteinized CWPS (ca. $100 \mathrm{~g} / 1$ lactose) without supplementation (Fig. 2; Table 2). In the initial batch (run 1), the yeast consumed ca. $60 \mathrm{~g} / \mathrm{l}$ lactose in about $48 \mathrm{~h}$, after which lactose consumption stopped and ethanol consumption was observed (Fig. 2). A second batch (run 2) was initiated after $128 \mathrm{~h}$ of operation. About $95 \%$ of the volume in the bioreactor was removed, with the sedimented yeast biomass left behind as inoculum for the second batch. A fraction of the biomass was lost along with the removal of the fermenting broth, which led to a reduction in yeast 


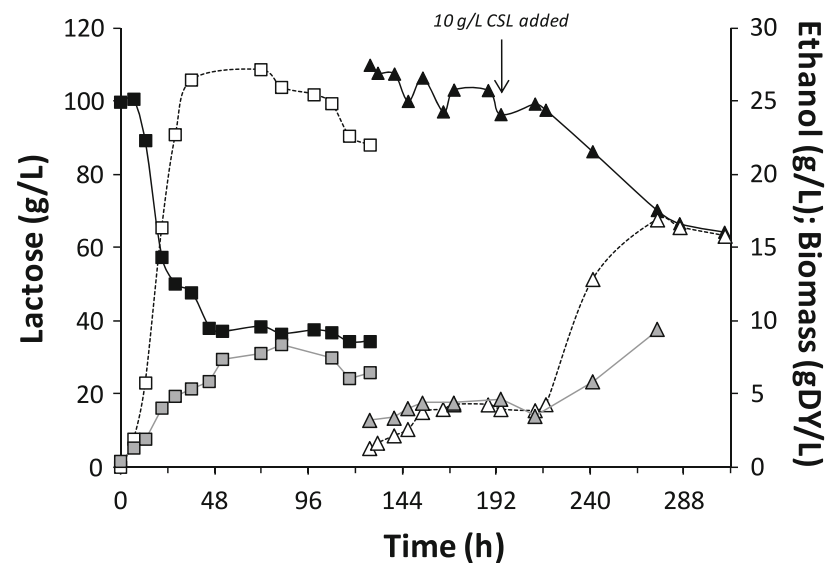

Fig. 2 Profiles of lactose (solid symbols, solid lines), ethanol (open symbols, dashed lines) and biomass (grey symbols, grey lines) concentrations during repeated-batch fermentations of concentrated whey without supplementation in the air-lift bioreactor: run 1 (squares); run 2 (triangles)

concentration from 7 to $4 \mathrm{~g} / \mathrm{l}$ (dry weight). During the initial $67 \mathrm{~h}$ of run 2, lactose consumption, yeast growth and ethanol production were very slow (Fig. 2). This long lag phase in the second batch possibly resulted from the prolonged stationary phase at the end of run $1(48-128 \mathrm{~h}$ in Fig. 2), during which yeast cells were probably subjected to several stresses, including ethanol and nutrient limitation. Therefore, we added $10 \mathrm{~g} / \mathrm{l} \mathrm{CSL}$, which restarted faster yeast growth and fermentation for further $80 \mathrm{~h}$, after which ethanol production stopped with a lactose residual of $70 \mathrm{~g} / \mathrm{l}$. These results suggested that the fermentations were impaired by nutrient limitation.
The bioreactor was then operated during five consecutive runs with deproteinized CWPS (112-145 g/l lactose) supplemented with $10 \mathrm{~g} / \mathrm{l} \mathrm{CSL}$ (Fig. 3; Table 2). Supplementation resulted in strongly improved fermentation performance in run 1 , in which the yeast was able to consume $108 \mathrm{~g} / \mathrm{l}$ lactose in $122 \mathrm{~h}$. Again, substantial biomass loss occurred during removal of the fermentation broth (decrease from 7 to $4 \mathrm{~g} / \mathrm{l}$ ) to initiate run 2 . In the second run, fermentation was faster with nearly total lactose consumption. The same level of yeast growth has occurred (ca. $8 \mathrm{gDY} / \mathrm{l}$ ) resulting in accumulation of biomass up to $12 \mathrm{gDY} / \mathrm{l}$, which diminished to $4 \mathrm{gDY} / 1$ during transfer to run 3 . In run 3 the whey concentration was increased to $145 \mathrm{~g} / \mathrm{l}$ lactose, which had a negative impact on fermentation performance (slower fermentation, higher lactose residual), and therefore in the subsequent runs the concentration of whey was again lowered to $112-117 \mathrm{~g} / \mathrm{l}$ lactose. Moreover, in the transfers for run 4 and 5, the fermentation broth was removed from an outlet port located in an upper position of the bioreactor (for details see "Materials and methods"), permitting the retention of a higher fraction of the flocculated biomass (8-9 gDY/l). The maximum yeast concentration reached in these last runs increased to $14-19 \mathrm{gDY} / \mathrm{l}$.

Expectedly, alcoholic fermentation was accompanied by the formation of glycerol, whose levels corresponded to $7-8 \%$ of the ethanol concentrations produced (Table 2). Under oxygen-limiting conditions, the pathways leading to glycerol biosynthesis act as a redox valve enabling the reoxidation of surplus NADH that is generated in anabolic reactions [40].

Table 2 Data obtained at the end of each run during repeated-batch fermentations of concentrated whey in the air-lift bioreactor

\begin{tabular}{|c|c|c|c|c|c|c|c|}
\hline \multirow[b]{2}{*}{ Fermentation run \# } & \multicolumn{2}{|c|}{ Non-supplemented } & \multicolumn{5}{|c|}{ Supplementation with $10 \mathrm{~g} / \mathrm{l} \mathrm{CSL}$} \\
\hline & 1 & 2 & 1 & 2 & 3 & 4 & 5 \\
\hline Initial lactose $(\mathrm{g} / \mathrm{l})$ & 99 & 110 & 114 & 112 & 145 & 117 & 112 \\
\hline Fermentation run time (h) & 72 & 147 & 64 & 70 & 97 & 73 & 76 \\
\hline Total process time $(\mathrm{h})$ & 72 & 275 & 64 & 193 & 308 & 381 & 457 \\
\hline Residual lactose (g/l) & 38 & 70 & 22 & 3 & 23 & 1 & 0 \\
\hline Ethanol produced $(\mathrm{g} / \mathrm{l})^{\mathrm{a}}$ & 27 & 16 & 41 & 51 & 50 & 51 & 49 \\
\hline Ethanol in the ferm. broth $(\mathrm{g} / \mathrm{l})$ & 27 & 17 & 41 & 54 & 53 & 65 & 64 \\
\hline Glycerol (g/l) & 2.1 & 1.5 & 2.8 & 3.6 & 3.7 & 3.8 & 3.8 \\
\hline Biomass dry weight (gDY/l) & 6.5 & 9.4 & 6.8 & 11.7 & 12.4 & 18.7 & 14.5 \\
\hline Ethanol yield (\% of theoretical $)^{\mathrm{b}}$ & 82 & 74 & 83 & 87 & 76 & 82 & 81 \\
\hline Ethanol productivity $(\mathrm{g} / \mathrm{l} / \mathrm{h})^{\mathrm{b}}$ & 0.74 & 0.11 & 0.64 & 0.73 & 0.52 & 0.70 & 0.64 \\
\hline Final yeast viability $(\%)^{\mathrm{c}}$ & $98 \pm 1$ & $97 \pm 1$ & $99 \pm 1$ & $97 \pm 2$ & $98 \pm 2$ & $99 \pm 1$ & $98 \pm 1$ \\
\hline Plasmid retention $(\%)^{\mathrm{c}}$ & $88 \pm 6$ & $83 \pm 3$ & $84 \pm 2$ & $86 \pm 2$ & $85 \pm 10$ & $87 \pm 3$ & $93 \pm 2$ \\
\hline
\end{tabular}

${ }^{a}$ The ethanol produced in each run corresponds to the ethanol in the fermentation broth minus the initial ethanol that was transferred from the previous run during yeast recycling

${ }^{b}$ Calculated based on the ethanol produced

${ }^{c}$ Values are average \pm standard deviation of at least four independent determinations 


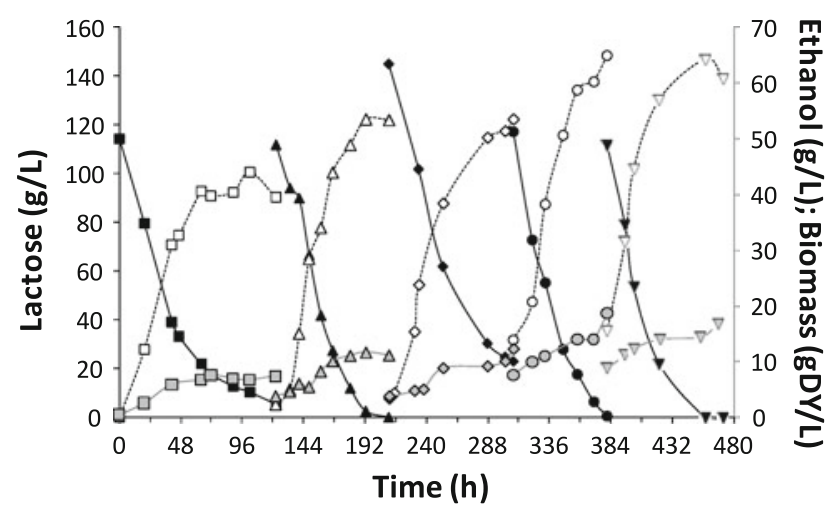

Fig. 3 Profiles of lactose (solid symbols, solid lines), ethanol (open symbols, dashed lines) and biomass (grey symbols, grey lines) concentrations during repeated-batch fermentations of concentrated whey supplemented with $10 \mathrm{~g} / \mathrm{l} \mathrm{CSL}$ in the air-lift bioreactor: run 1 (squares); run 2 (triangles); run 3 (diamonds); run 4 (circles); run 5 (inverted triangles)

Cultivation of the recombinant strain in media containing lactose as the sole carbon source provides positive selection for plasmid-bearing cells, since the cells that do not carry the plasmid due to segregational instability during division do not express the $L A C$ genes and consequently are unable to use lactose $[8,13]$. In the supplemented fermentations, the use of other assimilable carbon sources present in CSL could lead to plasmid loss. However, the fraction of yeast cells retaining the plasmid at the end of fermentations was high (>82\%) regardless of CSL supplementation (Tables 1,2). This high plasmid stability in strain T1-E is consistent with our previous observations in mineral medium cultivations [13], and indicates that the strain can be genetically stable for industrial utilization.

The ethanol produced increased from $41 \mathrm{~g} / \mathrm{l}$ in run 1 to $49-51 \mathrm{~g} / 1$ in the subsequent runs, corresponding to high lactose to ethanol conversion yields (above $80 \%$ of theoretical) (Table 2). Moreover, accumulation of ethanol from the previous runs (due to the retention of approximately $20 \% \mathrm{v} / \mathrm{v}$ of the fermentation broth in the fermenter during yeast recycling) resulted in higher ethanol titers $(64-65 \mathrm{~g} / \mathrm{l}$, i.e., ca. $8 \% \mathrm{v} / \mathrm{v}$ ) at the end of runs 4 and 5 (Table 2), which may be beneficial for reducing the distillation costs. The overall average ethanol productivity in the bioreactor repeated-batch process was $0.65 \mathrm{~g} / \mathrm{l} / \mathrm{h}$, which represents a 1.4-fold increase compared to the previously obtained in fermentation of concentrated cheese whey in a stirred-tank bioreactor [13]. Nevertheless, this productivity was much lower than that observed in the shake-flasks fermentations with CSL supplementation $(1.2 \mathrm{~g} / \mathrm{l} / \mathrm{h}$; Table 1$)$.

Table 3 provides an outline of literature reports on batch whey-to-ethanol fermentation processes, including recombinant $S$. cerevisiae strains and natural lactose-fermenting yeasts. There are very few reports on fermentation of whey by lactose-consuming recombinant $S$. cerevisiae. The data in Table 3 clearly show that strain T1-E produced much higher ethanol concentration than other recombinant lactose-consuming S. cerevisiae, with similar or higher batch productivity. Among the works on whey fermentation by natural lactose-fermenting yeasts, a few report higher ethanol titers but considerably lower productivities $[9,22]$ compared to this work. Conversely, some report higher productivity but lower ethanol titer $[11,12,17,46]$. Only two papers report simultaneously higher ethanol titer and higher productivity [20,43] than obtained in this work. Nevertheless, it is noteworthy that in one of those works [20] the whey was supplemented with peptone, which is more expensive than CSL, therefore representing a drawback for industrial implementation.

In industrial practice, the whey-to-ethanol Carbery process is the most common, being first introduced in Ireland and later adopted by plants in New Zealand and the United States [29]. In this process, fermentation by $K$. marxianus takes $12-20 \mathrm{~h}$ (depending on the initial lactose concentration and yeast activity) yielding a product with $2.5-3.5 \%$ ethanol [29], representing an average productivity of $1.5 \mathrm{~g} / \mathrm{l} / \mathrm{h}$. Despite the lower productivity, the repeated-batch process described here results in much higher ethanol titer, with consequent economic savings in distillation.

In addition, the process hereby presented has several other advantages from the industrial standpoint. First, the strain T1-E flocculated well in the CWPS allowing fast, simple, and inexpensive biomass recycling for repeatedbatch operation during at least five consecutive fermentation runs. Second, the yeast viability and the plasmid stability remained high throughout the process (Table 2), demonstrating that the strain is genetically stable and robust for industrial utilization. Finally, due to the substantial buffering capacity of the whey solutions, a $\mathrm{pH}$ control system was unnecessary, which simplifies industrial operation $[4,10]$. The deproteinized CWPS were acidified to minimize bacterial contamination and the $\mathrm{pH}$ kept at $4.2 \pm 0.2$ during fermentations.

\section{Conclusions}

The recombinant flocculent $S$. cerevisiae strain T1-E was tested for the production of bio-ethanol from deproteinized CWPS. Supplementation with $10 \mathrm{~g} / \mathrm{l}$ CSL strongly enhanced fermentation of concentrated whey $(150 \mathrm{~g} / \mathrm{l} \mathrm{lac}$ tose), enabling the production of $7.4 \%(\mathrm{v} / \mathrm{v})$ ethanol in shake-flasks with an overall productivity of $1.2 \mathrm{~g} / \mathrm{l} / \mathrm{h}$. A repeated-batch process was stably operated during five consecutive fermentation runs in an air-lift bioreactor with cell recycling by flocculation (without a costly centrifugation step) and without the need for $\mathrm{pH}$ control system. 


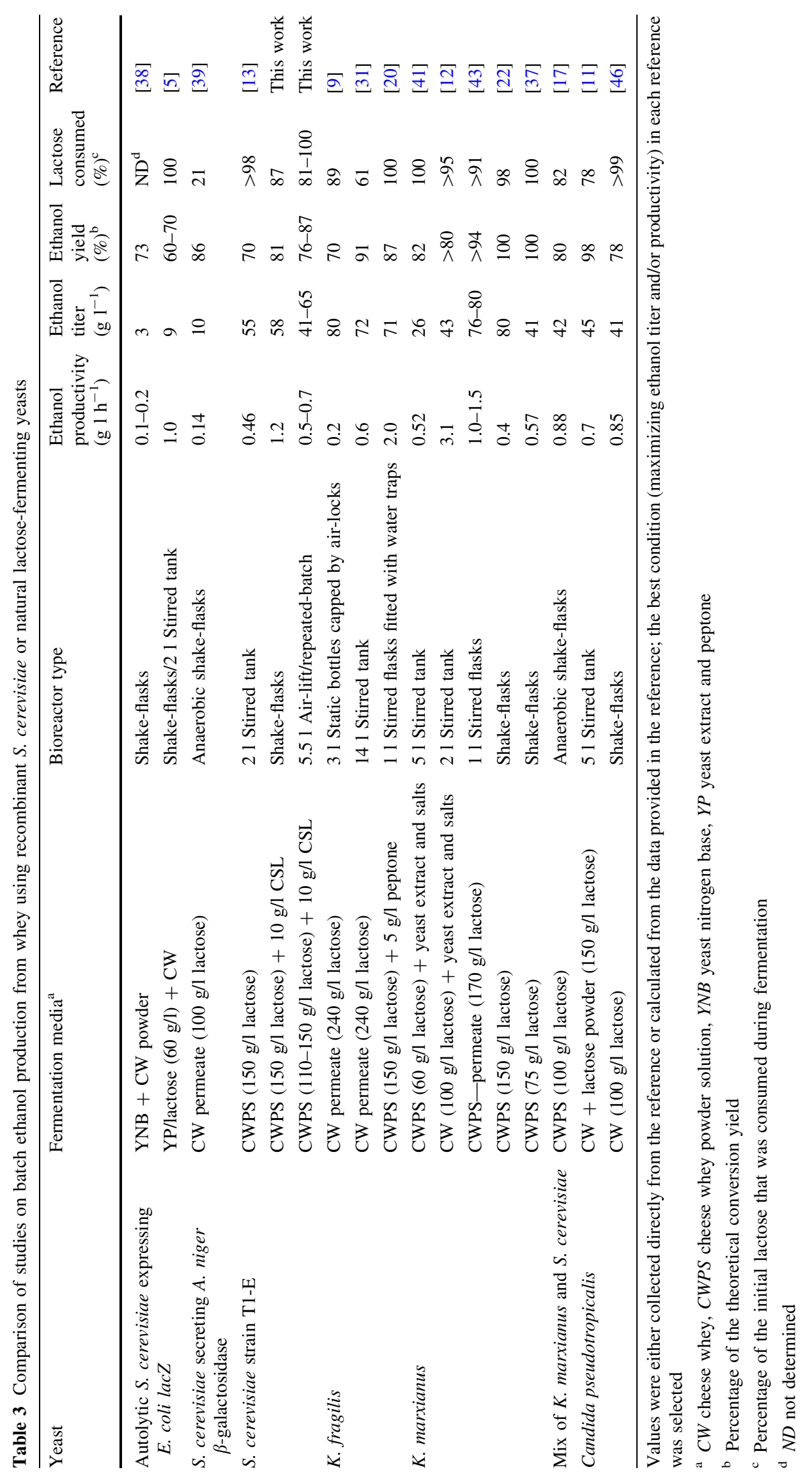


During this process, the average ethanol productivity was $0.65 \mathrm{~g} / \mathrm{l} / \mathrm{h}$ and ethanol accumulated up to $8 \%(\mathrm{v} / \mathrm{v})$ with conversion yields over $80 \%$.

Acknowledgments The authors thank André Mota for assistance in setting up the bioreactor fermentations, LACTOGAL-Produtos Alimentares S.A. (Portugal) for kindly providing the cheese whey powder and COPAM-Companhia Portuguesa de Amidos, S.A. (Portugal) for kindly providing the CSL. The financial support of Fundação para a Ciência e a Tecnologia (FCT), Portugal, is acknowledged (project ProBioethanol PTDC/BIO/66151/2006 and grant SFRH/BPD/44328/2008 to P. M. R. Guimarães).

\section{References}

1. Agarwal L, Dutt K, Meghwanshi GK, Saxena RK (2008) Anaerobic fermentative production of lactic acid using cheese whey and corn steep liquor. Biotechnol Lett 30:631-635

2. Amartey S, Jeffries TW (1994) Comparison of corn steep liquor with other nutrients in the fermentation of D-xylose by Pichia stipitis CBS 6054. Biotechnol Lett 16:211-214

3. Casey GP, Ingledew WMM (1986) Ethanol tolerance in yeasts. CRC Crit Rev Microbiol 13:219-280

4. Choi GW, Kang HW, Moon SK (2009) Repeated-batch fermentation using flocculent hybrid, Saccharomyces cerevisiae CHFY0321 for efficient production of bioethanol. Appl Microbiol Biotechnol 84:261-269

5. Compagno C, Porro D, Smeraldi C, Ranzi BM (1995) Fermentation of whey and starch by transformed Saccharomyces cerevisiae cells. Appl Microbiol Biotechnol 43:822-825

6. Domingues L, Guimarães PMR, Oliveira C (2010) Metabolic engineering of Saccharomyces cerevisiae for lactose/whey fermentation. Bioengineered Bugs 1 (in press)

7. Domingues L, Lima N, Teixeira JA (2001) Alcohol production from cheese whey permeate using genetically modified flocculent yeast cells. Biotechnol Bioeng 72:507-514

8. Domingues L, Teixeira JA, Lima N (1999) Construction of a flocculent Saccharomyces cerevisiae fermenting lactose. Appl Microbiol Biotechnol 51:621-626

9. Gawel J, Kosikowski FV (1978) Improving alcohol fermentation in concentrated ultrafiltration permeates of cottage cheese whey. J Food Sci 43:1717-1719

10. Ghaly AE, El-Taweel AA (1997) Continuous ethanol production from cheese whey fermentation by Candida pseudotropicalis. Energy Sources A Recover Util Environ 19:1043-1063

11. Ghaly AE, El-Taweel AA (1995) Effect of micro-aeration on the growth of Candida pseudotropicalis and production of ethanol during batch fermentation of cheese whey. Bioresour Technol 52:203-217

12. Grba S, Stehlik-Tomas V, Stanzer D, Vahcic N, Skrlin A (2002) Selection of yeast strain Kluyveromyces marxianus for alcohol and biomass production on whey. Chem Biochem Eng Q 16:13-16

13. Guimarães PMR, François J, Parrou JL, Teixeira JA, Domingues L (2008) Adaptive evolution of a lactose-consuming Saccharomyces cerevisiae recombinant. Appl Environ Microbiol 74:1748-1756

14. Guimarães PMR, Teixeira JA, Domingues L (2008) Fermentation of high concentrations of lactose to ethanol by engineered flocculent Saccharomyces cerevisiae. Biotechnol Lett 30:1953-1958

15. Guimarães PMR, Teixeira JA, Domingues L (2010) Fermentation of lactose to bio-ethanol by yeasts as part of integrated solutions for the valorisation of cheese whey. Biotechnol Adv 28:375-384

16. Guimarães PMR, Virtanen H, Londesborough J (2006) Direct evidence that maltose transport activity is affected by the lipid composition of brewer's yeast. J Inst Brew 112:203-209
17. Guo X, Zhou J, Xiao D (2010) Improved ethanol production by mixed immobilized cells of Kluyveromyces marxianus and Saccharomyces cerevisiae from cheese whey powder solution fermentation. Appl Biochem Biotechnol 160:532-538

18. Hahn-Hägerdal B, Karhumaa K, Larsson CU, Gorwa-Grauslund M, Gorgens J, van Zyl WH (2005) Role of cultivation media in the development of yeast strains for large-scale industrial use. Microb Cell Fact 4:31

19. Huang Y, Yang ST (1998) Acetate production from whey lactose using co-immobilized cells of homolactic and homoacetic bacteria in a fibrous-bed bioreactor. Biotechnol Bioeng 60:498-507

20. Janssens JH, Burris N, Woodward A, Bailey RB (1983) Lipidenhanced ethanol production by Kluyveromyces fragilis. Appl Environ Microbiol 45:598-602

21. Kadam KL, Newman MM (1997) Development of a low-cost fermentation medium for ethanol production from biomass. Appl Microbiol Biotechnol 47:625-629

22. Kargi F, Ozmihci S (2006) Utilization of cheese whey powder (CWP) for ethanol fermentations: effects of operating parameters. Enzyme Microbiol Technol 38:711-718

23. Kim HO, Wee YJ, Kim JN, Yun JS, Ryu HW (2006) Production of lactic acid from cheese whey by batch and repeated batch cultures of Lactobacillus sp. RKY2. Appl Biochem Biotechnol 131:694-704

24. Klein J, Maia J, Vicente AA, Domingues L, Teixeira JA, Jurascik M (2005) Relationships between hydrodynamics and rheology of flocculating yeast suspensions in a high-cell-density airlift bioreactor. Biotechnol Bioeng 89:393-399

25. Koutinas AA, Athanasiadis I, Bekatorou A et al (2007) Kefiryeast technology: industrial scale-up of alcoholic fermentation of whey, promoted by raisin extracts, using kefir-yeast granular biomass. Enzyme Microbiol Technol 41:576-582

26. Lawford HG, Rousseau JD (1997) Corn steep liquor as a costeffective nutrition adjunct in high-performance Zymomonas ethanol fermentations. Appl Biochem Biotechnol 63-5:287-304

27. Lee PC, Lee SY, Hong SH, Chang HN (2003) Batch and continuous cultures of Mannheimia succiniciproducens MBEL55E for the production of succinic acid from whey and corn steep liquor. Bioprocess Biosyst Eng 26:63-67

28. Li F, Zhao XQ, Ge XM, Bai FW (2009) An innovative consecutive batch fermentation process for very high gravity ethanol fermentation with self-flocculating yeast. Appl Microbiol Biotechnol 84:1079-1086

29. Ling KC (2008) Whey to ethanol: a biofuel role for dairy cooperatives? USDA Rural Development, Research Report 214, Washington, DC

30. Ma K, Wakisaka M, Sakai K, Shirai Y (2009) Flocculation characteristics of an isolated mutant flocculent Saccharomyces cerevisiae strain and its application for fuel ethanol production from kitchen refuse. Bioresour Technol 100:2289-2292

31. Mahmoud MM, Kosikowski FV (1982) Alcohol and single cell protein production by Kluyveromyces in concentrated whey permeates with reduced ash. J Dairy Sci 65:2082-2087

32. Miller GL (1959) Use of dinitrosalicylic acid reagent for determination of reducing sugar. Anal Chem 31:426-428

33. Mills DR (1941) Differential staining of living and dead yeast cells. Food Res 6:361-371

34. Oda Y, Nakamura K (2009) Production of ethanol from the mixture of beet molasses and cheese whey by a 2-deoxyglucose-resistant mutant of Kluyveromyces marxianus. FEMS Yeast Res 9:742-748

35. Ozmihci S, Kargi F (2007) Effects of feed sugar concentration on continuous ethanol fermentation of cheese whey powder solution (CWP). Enzyme Microbiol Technol 41:876-880

36. Ozmihci S, Kargi F (2007) Ethanol fermentation of cheese whey powder solution by repeated fed-batch operation. Enzyme Microbiol Technol 41:169-174 
37. Ozmihci S, Kargi F (2007) Kinetics of batch ethanol fermentation of cheese-whey powder (CWP) solution as function of substrate and yeast concentrations. Bioresour Technol 98:2978-2984

38. Porro D, Martegani E, Ranzi BM, Alberghina L (1992) Lactose/ whey utilization and ethanol production by transformed Saccharomyces cerevisiae cells. Biotechnol Bioeng 39:799-805

39. Ramakrishnan S, Hartley BS (1993) Fermentation of lactose by yeast cells secreting recombinant fungal lactase. Appl Environ Microbiol 59:4230-4235

40. Rigoulet M, Aguilaniu H, Averet N et al (2004) Organization and regulation of the cytosolic NADH metabolism in the yeast Saccharomyces cerevisiae. Mol Cell Biochem 256-257:73-81

41. Rosenberg M, Tomaska M, Kanuch J, Sturdik E (1995) Improved ethanol production from whey with Saccharomyces cerevisiae using permeabilized cells of Kluyveromyces marxianus. Acta Biotechnol 15:387-390

42. Roy D, Goulet J, Leduy A (1986) Batch fermentation of whey ultrafiltrate by Lactobacillus helveticus for lactic acid production. Appl Microbiol Biotechnol 24:206-213

43. Silveira WB, Passos F, Mantovani HC, Passos FML (2005) Ethanol production from cheese whey permeate by Kluyveromyces marxianus UFV-3: a flux analysis of oxido-reductive metabolism as a function of lactose concentration and oxygen levels. Enzyme Microbiol Technol 36:930-936

44. Siso MIG (1996) The biotechnological utilization of cheese whey: a review. Bioresour Technol 57:1-11

45. Smithers GW (2008) Whey and whey proteins-from 'gutter-togold'. Int Dairy J 18:695-704

46. Szczodrak J, Szewczuk D, Rogalski J, Fiedurek J (1997) Selection of yeast strain and fermentation conditions for high-yield ethanol production from lactose and concentrated whey. Acta Biotechnologica 17:51-61

47. Tang Y, An M, Liu K et al (2006) Ethanol production from acid hydrolysate of wood biomass using the flocculating yeast Saccharomyces cerevisiae strain KF-7. Process Biochem 41:909-914

48. Verduyn C, Postma E, Scheffers WA, van Dijken JP (1992) Effect of benzoic acid on metabolic fluxes in yeasts: a continuous-culture study on the regulation of respiration and alcoholic fermentation. Yeast 8:501-517

49. Zhang J, Reddy J, Buckland B, Greasham R (2003) Toward consistent and productive complex media for industrial fermentations: studies on yeast extract for a recombinant yeast fermentation process. Biotechnol Bioeng 82:640-652 